http://jmscr.igmpublication.org/home/

ISSN (e)-2347-176x ISSN (p) 2455-0450

crossref DOI: https://dx.doi.org/10.18535/jmscr/v9i3.02

Journal Of Medical Science And Clinical Research

\title{
Stauffer's Syndrome: A Rare Case Report
}

\section{Authors \\ Dr Himesh Gandhi ${ }^{1}$, Dr Bhondave S.T. ${ }^{2}$, Dr Manoj Shrivastav ${ }^{3}$, Dr Aman Gupta ${ }^{2}$, Dr Tarun Singh ${ }^{2}$}

${ }^{1}$ Senior Consultant Uro-oncologist and Director of Robotics Surgery, Department of Urology, Ruby Hall Clinic, Pune

${ }^{2}$ Senior Resident, Department of Urology, Ruby Hall Clinic, Pune

${ }^{3}$ Senior Hepatobiliary Consultant and Liver transplant Surgeon, Ruby Hall Clinic, Pune

Abstract
Background: Stauffer's syndrome is non- metastatic liver dysfunction in patients suffering from renal
cell carcinoma (RCC). It is one of the rare variant of paraneoplastic syndrome associated with RCC. It is
related to several biochemical abnormalities and production of cytokines by the tumor.
Case Presentation: We present a 44 years old male patient with left renal and adrenal mass, who had
isolated elevation of liver enzymes. Patient underwent robotic radical nephrectomy converted to open
radical nephrectomy with left adrenalectomy with complete resolution of syndrome features.
Conclusion: Stauffer's syndrome should be kept in mind when patient having hepatic dysfunction with or
without jaundice with confirmed or suspicious renal mass presents to clinicians after ruling out all other
etiologies.

\section{Introduction}

Stauffer's syndrome is a rare clinical condition with incidence ranging between $3 \%$ to $6 \%$ in patients with renal cell carcinoma (RCC). ${ }^{(1,2)}$ It is one of the most characteristic paraneoplastic syndromes associated with RCC. In 1961, first described by Herbert Stauffer in patients suffering from RCC, abnormal liver function tests, hepatosplenomagaly, histologic changes consistent with non specific hepatitis with reversal of these changes after nephrectomy. Of all cancers RCC accounts for only $2 \%$. Classic triad of RCC is found in $10 \%$ of patients which includes flank pain, hematuria and palpable abdominal mass. ${ }^{(3)}$ It is also related with many paraneoplastic syndromes ranging from anemia, polycythemia, malignant hypercalcemia and liver dysfunction. ${ }^{(4)}$ In $10 \%$ to $15 \%$ of RCC, in absence of liver metastasis, hepatic dysfunction occurs due to production of cytokines from the tumor. ${ }^{(5,6)}$

In our case we have encountered a 44 years old male patient with left renal and adrenal mass, who had isolated elevation of liver enzymes and underwent robotic radical nephrectomy converted to open radical nephrectomy with left adrenalectomy with complete resolution of syndrome features.

\section{Case Report}

A 44 year old male patient, presented with pain in the left flank region since 1.5 years with its aggravation in last 2 months. Patient had 
undergone coronary artery bypass graft (CABG) 2 months back for ischemic heart disease. On examination there was tenderness present in left lumbar and hypochondrium. The remainder of examination was normal. Laboratory abnormality prominently identified was isolated elevation in liver enzymes as aspartate transaminase at 240 $\mathrm{U} / \mathrm{L}$ (normal $<40 \mathrm{U} / \mathrm{L}$ ), alanine transaminase at $354 \mathrm{U} / \mathrm{L}$ (normal<56 U/L), alkaline phosphatase at $209 \mathrm{U} / \mathrm{L}$ (normal<129 U/L) and gamma glutamyltransferase at $477 \mathrm{U} / \mathrm{L}$ (normal<61 U/L). Total bilirubin was $0.7 \mathrm{mg} / \mathrm{dl}$. Haemoglobin was $11.4 \mathrm{~g} / \mathrm{dl}$, white cell count $10,090 / \mathrm{mm}^{3}$, platelets $409,000 / \mathrm{mm}^{3}$, prothrombin time/ International normalized ratio 14.4/1.23, erythrocyte sedimentation rate $80 \mathrm{~mm} / \mathrm{h}$, IL-6 at $40 \mathrm{pg} / \mathrm{ml}$ (normal <6.4 pg/ml). HIV, HAV, HEV were non reactive. Immunologic investigations showed absence of anti- nuclear and antimitochondrial antibodies. Urine routine microscopy showed no pus cells and red blood cells and urine culture was sterile.

On abdominal ultrasonography (figure 1), mild generalized hepatomegaly was noted, both kidneys were normal in size, shape and position, $4.3 \mathrm{~cm} \times 3.0 \mathrm{~cm}$ well defined hypoechoic lesion was noted at mid and lower pole of left kidney suggestive of renal mass with $12 \mathrm{~mm} \times 11 \mathrm{~mm}$ tiny hypoechoic lesion noted at left adrenal. 4 to 6 left paraaortic lymph nodes were noted largest measuring $49 \mathrm{~mm}$ x $32 \mathrm{~mm}$.

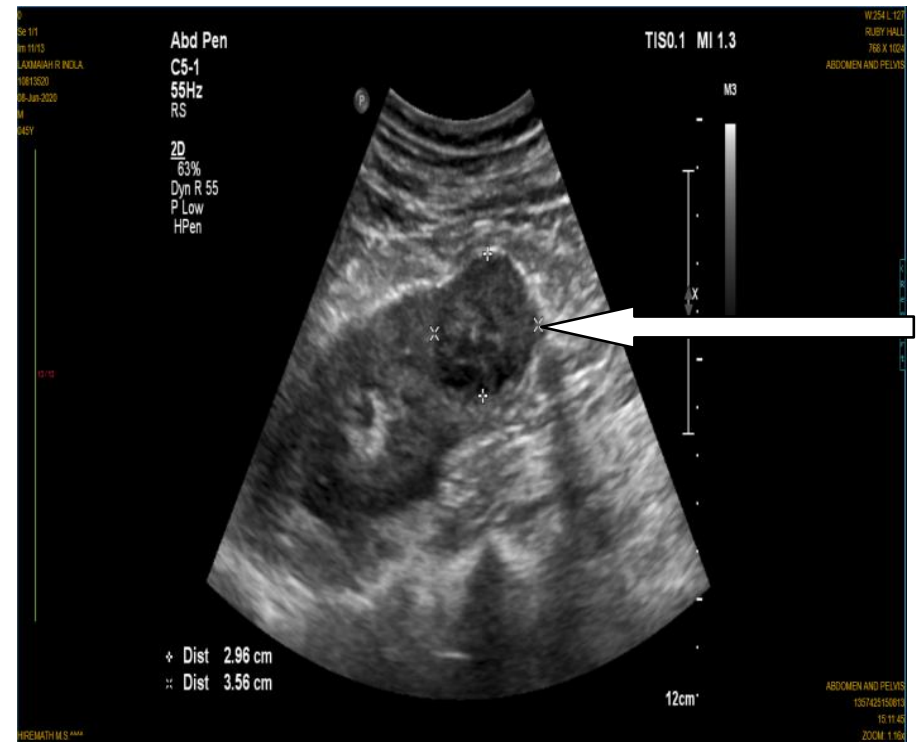

Figure 1- Ultrasonography of left kidney showing left renal mass

Contrast enhanced computed tomography (CECT) abdomen and pelvis was performed one week prior to surgery which confirmed findings of ultrasonography, showing heterogenous mass at lower pole of left kidney with left paraaortic and interaorto- caval lymphadenopathy (figure 2). Liver, left renal vein and contralateral kidney was normal. Chest CT showed no distant metastasis. Hepatologist was consulted and they suggested Stauffer paraneoplastic syndrome. 


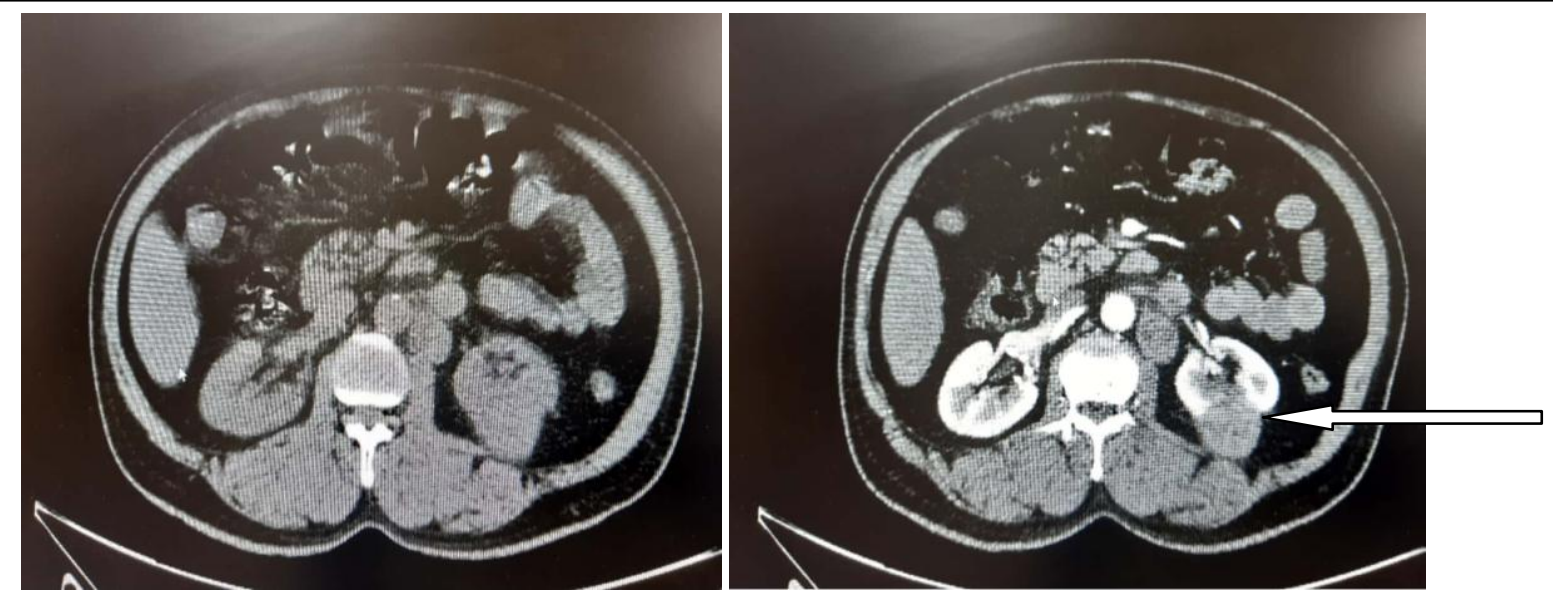

Figure 2 - CECT abdomen and pelvis showing left renal mass and left paraaortic and interaorto- caval lymphadenopathy

Patient was scheduled for robotic assisted radical nephrectomy with left adrenalectomy. Left renal artery ligated. Intraoperatively leverage on left renal vein was not possible due to peri-hilar lymphadenopathy. Conversion to open surgery was done. Thrombus was identified in left renal vein, thrombectomy done. Left nephrectomy with adrenalectomy with left para aortic lymphadenectomy was done. Drain was placed in left renal fossa and abdomen closed in layers. Post operative period was uneventful. On post operative day 1 , value of aspartate transaminase was $34 \mathrm{U} / \mathrm{L}$, alanine transaminase was $74 \mathrm{U} / \mathrm{L}$, alkaline phosphatase at $30 \mathrm{U} / \mathrm{L}$ and gamma glutamyltransferase at $243 \mathrm{U} / \mathrm{L}$. Surgical pathology showed high grade tumor arranged in solid, nested and papillary pattern. Unusual morphology showing rhabdoid and sarcomatoid changes with presence of papillary and clear cell areas with involved para-aortic lymph nodes (figure $3 \&$ 4). Immunohistochemistry was performed and immunophenotype was consistent with papillary renal cell carcinoma. Combined morphological and immunohistochemical features were suggestive of type 2 papillary renal cell carcinoma. At 1 month of follow up, serum concentration of liver enzymes had returned to normal and hepatomegaly resolved confirmed with ultrasonography.

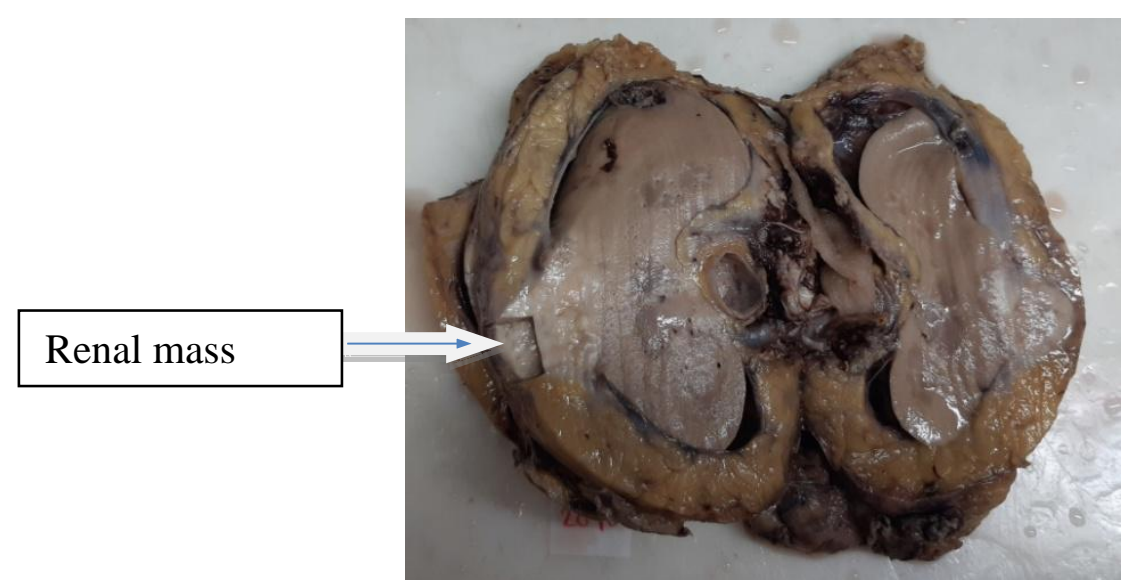

Figure 3- Left renal mass on gross histopathology 


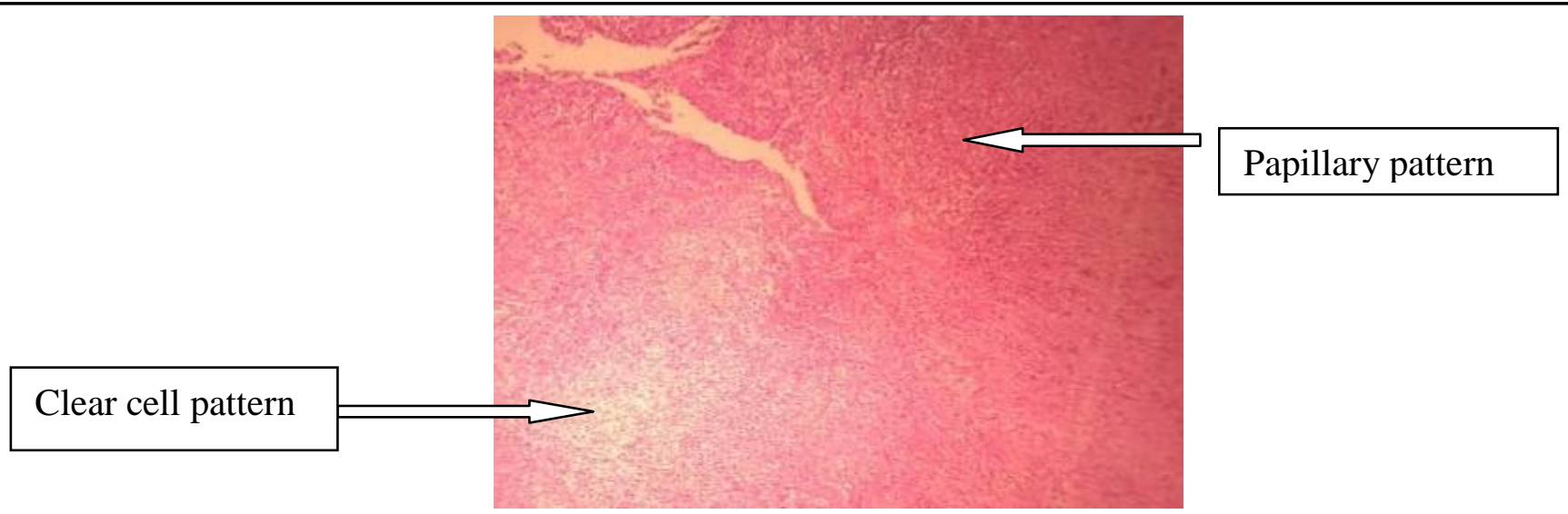

Figure 4- Clear cell and papillary pattern on microscopy

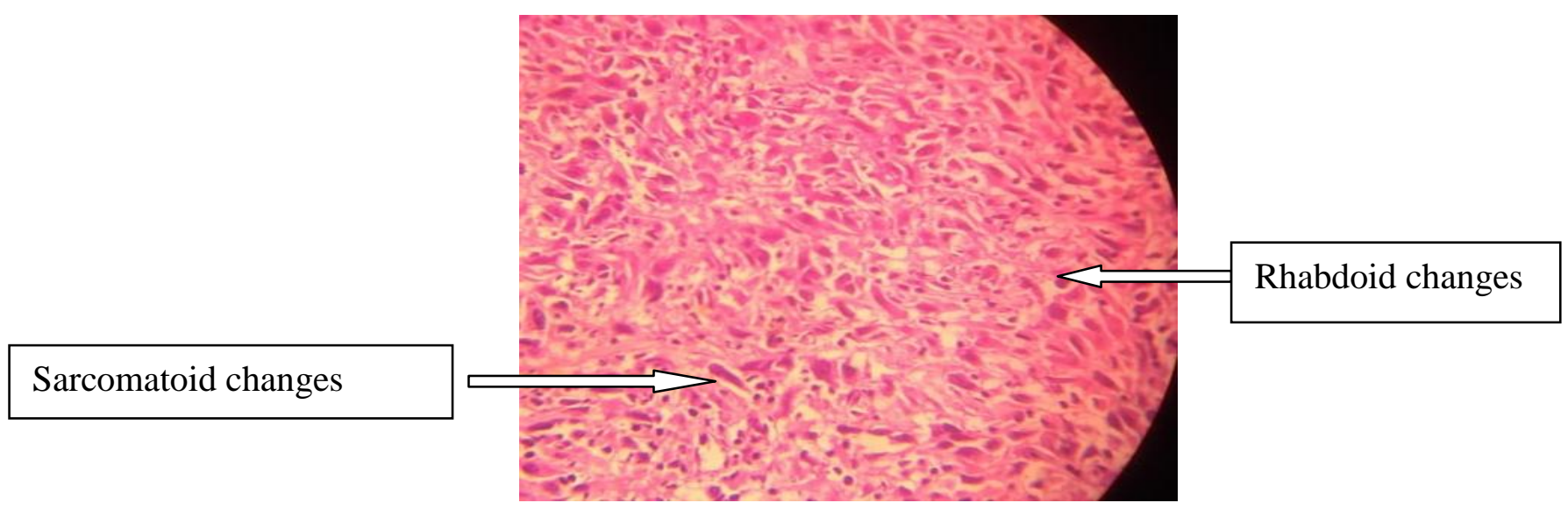

Figure 5 - Rhabdoid and sarcomatoid changes on microscopy

\section{Discussion}

RCC constitutes a paradigm of latent disease and it is characterized by varied and uncertain manifestations. ${ }^{(7)}$ Stauffer syndrome is usually associated with RCC and is an uncommon paraneoplastic syndrome. ${ }^{(2,5)}$ It can present with other type of malignancies as malignant lymphoproliferative diseases, prostate cancer and soft tissue sarcoma. ${ }^{(8,9)}$ Stauffer's syndrome has classic presentation and jaundice variant. Jaundice is uncommon, while anicteric intrahepatic cholestasis is the main form of Stauffer's syndrome. $^{(6,10)}$ In our case also patient was anicteric and had isolated elevation of liver enzymes.

The main role in the pathophysiology of this syndrome is proposed to be played by Interleukin6 (IL-6). ${ }^{(2,6,8)}$ Patients who had significantly higher hepatic compromise with elevated LFTs had detectable IL-6. ${ }^{(6)}$ Study conducted treating patients with Stauffer's syndrome with anti-IL-6 monoclonal antibodies found that it reversed most of the biochemical abnormalities of these patients. ${ }^{(11)}$ Humoral mediators have been proposed such as increase in lysosomal enzyme activity in liver cells of patients with RCC. ${ }^{(2)}$ Inspite of the findings mentioned, the precise mechanism of the disease remains poorly understood.

The markedly elevated liver enzymes was the main laboratory abnormality. Primary biliary cirrhosis and primary sclerosing cholangitis were highly unlikely diagnosis in view of the negative immunologic investigations.

Stauffers's syndrome remains a clinical diagnosis as currently there are no diagnostic criteria for it. Full liver screen should be undertaken for seeing any underlying pathology for liver derangement and hepatologist consultation for futher management guidance is required.

Since nephrectomy normalizes the deranged liver enzymes, it should be done on promt basis. The 
postoperative course can be predicted by monitoring the liver function tests. In patients with non- metastatic hepatic dysfunction with RCC, Stauffer's syndrome should be suspected and appropriate work up done to make an early diagnosis and increase chances of operative success.

\section{Conclusion}

Unusual presentation of RCC is rare, but surgeons should be aware of RCC's propensity to present as broad spectrum of non-renal, atypical manifestations.

\section{Conflicts of Interest: None}

\section{Consent}

Written informed consent was obtained from the patient for publication of this case report and accompanying images.

\section{References}

1. Boxer RJ, Waisman J, Lieber MM, Mampaso FM, Skinner DJ. Non metastatic hepatic dysfunction associated with renal carcinoma. J Urol. 1978;119(4):468-71.

2. Sharma N, Darr U, Sood G. Stauffer syndrome: a comprehensive review of the icteric variant of the syndrome. Cureus. 2019;11(10):6032.

3. Stauffer MH: Nephrogenic Hepatosplenomegaly. Gastroenterology 1961;40:694-96.

4. Gold PJ, Fefer A, Thompson JA. Paraneoplastic manifestations of renal cell carcinoma. Semin Urol Oncol.1996; 14(4):216-22.

5. Boxer RJ, Waisman J, Lieber MM, Mampaso FM, Skinner DJ. Non metastatic hepatic dysfunction associated with renal carcinoma. J Urol. 1978;119(4):468-71.

6. Blay JY, Rossi JF, Wijdenes J, et al. Role of interleukin-6 in the paraneoplastic inflammatory syndrome associated with renal cell carcinoma. Int $\mathrm{J}$ Cncer 1997;72(3):424-30.

7. Fuhrman SA, Lasky LC, Limas C. Prognostic significance of morphologic parameters in renal cell carcinoma. Am J SurgPathol 1982;6:655-63.

8. Fontes-Sousa M, Magalhaes H, da Silva FC, Mauricio MJ. Stauffer's syndrome: a comprehensive review and proposed updated diagnostic criteria. Urol Oncol Semin Orig Investig. 2018;36(7):321-26.

9. Dourakis SP, Sinai $C$, Deutsch $M$, Dimitriadou E, Hadziyannis SJ. Cholestatic jaundice as a paraneoplastic manifestation of renal cell carcinoma. Eur J GastroenterolHepatol 1997;9:311-314.

10. Giannakos G, Papanicolaou X, Trafalis D, Michaelidis I, Margaritis G, Christofilakis C. Stuffer's syndrome variant associated with renal cell carcinoma. Int $\mathbf{J}$ Urol 2005;12:757-59.

11. Karakolios A, Kasapis C, Kallinikidis T, et al. Cholestatic jaundice as a paraneoplastic manifestation of prostate adenocarcinoma. Clin Gastroenterol Hepatol. 2003;1(6): 480-83. 